\title{
INTRA-ARTICULAR RHEUMATOID NODULES OF THE KNEE
}

\author{
M. Anne Chamberlain, London, England \\ From the Arthur Stanley House, Middlesex Hospital, London
}

Rheumatoid nodules commonly occur at the elbow where subcutaneous tissue is subject to recurrent pressure against bone. They have also been reported in several other sites, such as in the flexor tendon sheaths, in the pulp of the fingers and adjacent to ribs (Johnson, Kersley and Airth 1970), where their presence may lead to attrition, rupture or erosion of adjacent structures. They may also occur in the lungs, when they may be associated with severe lung disease or may be a radiological finding only.

There are no reports of intra-articular nodules of sufficient size to cause mechanical symptoms. The eight patients described below all had rheumatoid nodules within the knee joint, producing recurrent instability and pain which was relieved by removal of the nodules.

\section{CLINICAL DETAILS}

The eight patients referred to were seen in the Department of Rheumatology at the Middlesex Hospital since July 1968. They all had severe or moderately severe rheumatoid arthritis. All but one had had extra-articular nodules (usually at the elbow) at some time. All had a positive test for rheumatoid factor (sheep-cell agglutination titre or latex test). Radiographs of seven patients were available and showed erosions, usually in the small joints of the hands or feet. All were women aged from thirty-two to sixty years who had had rheumatoid arthritis for two to seventeen years. Four had nodules in both knees, so that a total of twelve knees was affected (Table I).

Six women complained of something which clicked and seven pointed to a lump which appeared to jump or slip in and out with flexion and extension of the knee. Only one patient failed to mention either, saying only that the knee felt as though it would give way. Four others had this feeling of instability and in two the knee had repeatedly given way. Sometimes a knee would lock and the patient would push the nodule into its former position to achieve full extension. There was sometimes temporary difficulty in walking from lack of full extension.

The size and site of the nodule was remarkably similar in all. It was situated over the lateral femoral condyle, and on palpation appeared to be attached to the capsule. It was

TABLE I

Characteristics of Knees Involved by Rheumatoid Nodules

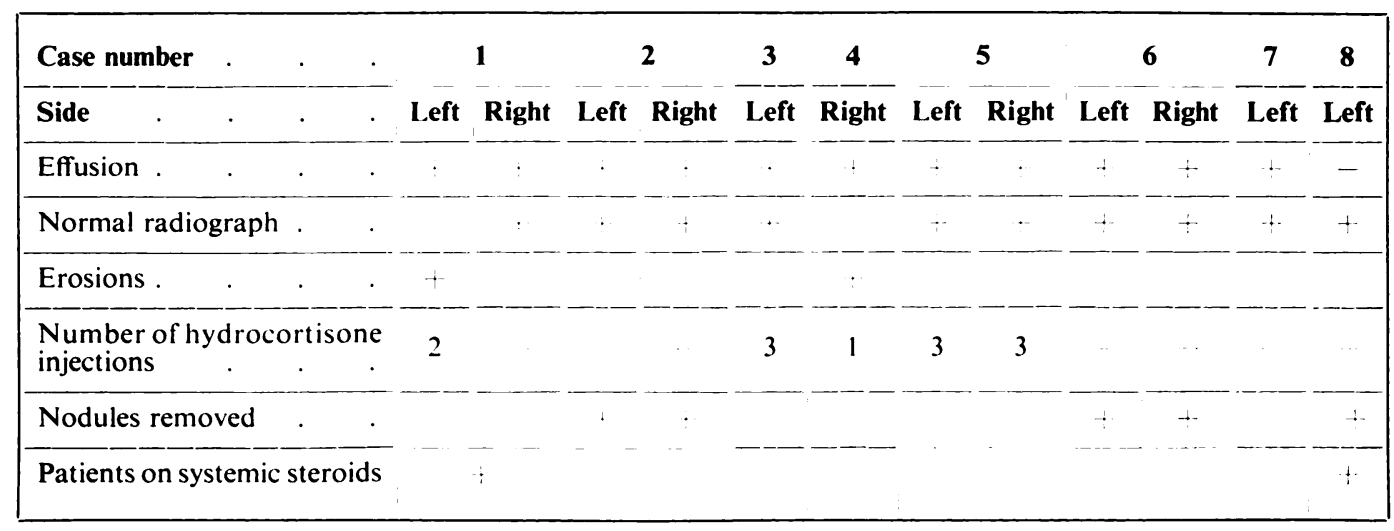


usually oval, in the line of the leg and about three centimetres long. Its limits were not always easy to define. The most constant and characteristic feature was the shift of position (the click) of a centimetre or so as it slipped over the underlying condyle. This occurred just as the knee reached about 15 degrees of flexion, at which point the nodule was most prominent.

Intra-articular injections of hydrocortisone acetate or administration of corticoids did not influence the occurrence of the nodules; four of the patients (five knees) had had intra-articular injections, but none more than three, and only two patients had received systemic corticosteroids (as prednisolone).

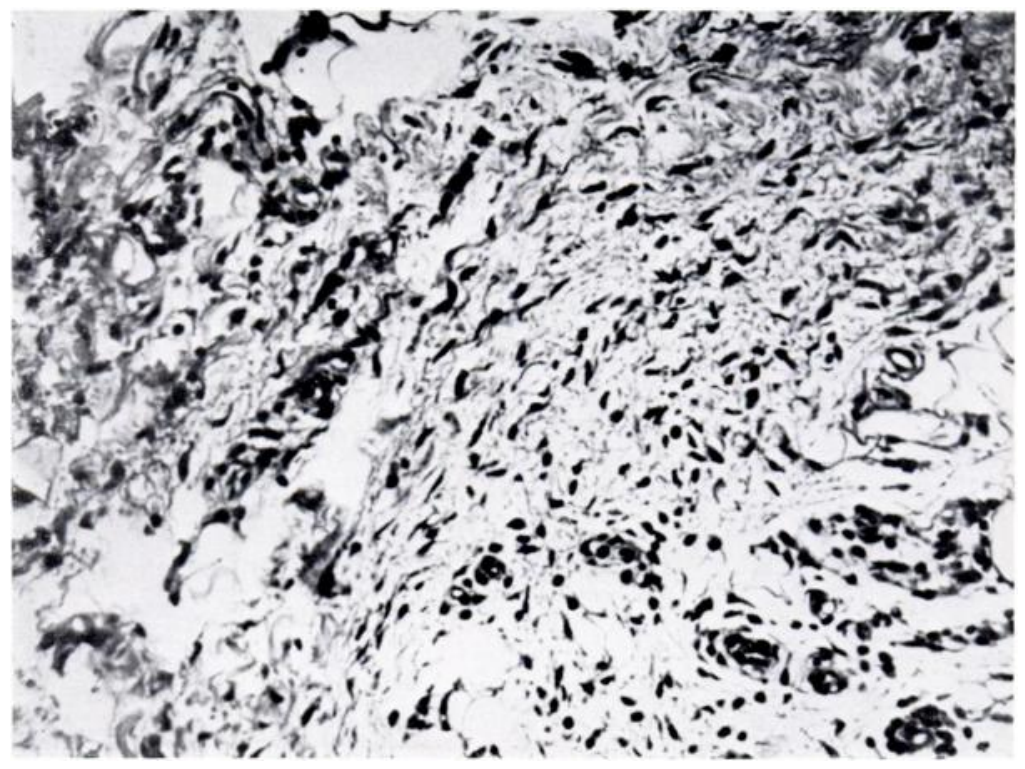

Fig. 1

The typical histological appearance of an intra-articular nodule.

Radiographs of the involved knees were normal in all but two in which some loss of joint space was found; no erosions could be seen in these two knees.

Operation and findings-Under general anaesthesia and with the limb exsanguinated, the knee joint was explored through a parapatellar incision overlying the nodule, which was always found to be tethered to the synovium adjacent to the patella. Local excision with a small cuff of synovium was all that proved necessary and the wound was closed in the usual way.

Microscopy confirmed that the intra-articular pedunculated nodules were all true rheumatoid nodules (Fig. 1). Each had the characteristic necrotic centre surrounded by palisades of fibroblasts which, in turn, were surrounded by a loose infiltrate of plasma cells and lymphocytes.

\section{DISCUSSION}

The nodules consisted of typical rheumatoid granulation tissue. They presented in the same way as any other attached body in the knee but could be recognised by the palpable lump in the characteristic position by its flicking over the lateral femoral condyle in flexion. The nodules were only found in patients with extensive polyarthritis associated with superficial nodules-usually at the elbow-and with positive serological tests.

The nodules have been recognised in our department for only two years, which is too short a time to observe the natural history. It is reasonable to suppose that the mechanical interference with joint function could, in time, lead to local degenerative changes although none was seen in our patients. Excision is justified in patients with troublesome symptoms. 


\section{SUMMARY}

1. Eight patients with rheumatoid arthritis had an intra-articular nodule in one or both knees causing mechanical symptoms.

2. The nodule was on the lateral side of the knee and interfered with walking. It caused a click and painful instability of the knee at about 15 degrees of flexion.

3. Surgical excision of the nodule, which was attached to the synovial membrane, abolished the symptoms.

I am most grateful for Mr Rodney Sweetnam's advice and encouragement; those patients whose nodules were excised were under his care and operated on by him or by Mr R. Dee. I should also like to acknowledge the generous help given by Dr A. C. Boyle and Dr Graham Perry.

\section{REFERENCE}

Johnson, C., Kersley, G. D., and Airth, G. R. (1970): Rib Lesions in Rheumatoid Disease. British Journal of Radiology, 43, 269.

VOL. 53 B, NO. 3, AUGUST 1971 